\title{
ТИОХОЛИНОВЫЕ ЭФИРЫ КАК СУБСТРАТЫ ХИМОТРИПСИНА
}

\author{
T. KESVATERA, Marika KOSK, A. AAVIKSAAR. TIOKOLIINI ESTRID KOMOTROPSIINI SUBST- \\ RAATIDENA \\ T. KESVATERA, Marika KOSK, A. AAVIKSAAR. THIOCHOLINE ESTERS AS SUBSTRATES FOR \\ CHYMOTRYPSIN
}

В работе представлены результаты исследования реакционной способности новых для химотрипсина субстратов, тиохолиновых эфиров алифатических карбоновых кислот $n=1-3$. Показано, что при химотрипсиновом гидролизе этих соединений время достижения стационарного состояния в трехстадийной реакции

$$
E+S \stackrel{\text { Ks }}{\rightleftharpoons} E S \stackrel{{ }^{k s}}{\underset{P_{1}}{\longrightarrow}} E A \stackrel{k_{s}}{\longrightarrow} E+P_{2}
$$

при $25^{\circ} \mathrm{C}$ и значениях $\mathrm{pH}$, близких к оптимальным, охватывает минуты, что позволяет регистрировать кинетику предстационарной фазы процесса на обычном спектрофотометре, используя метод Эллмана [1] для определения выделяющегося тиохолина, и получать значения $K_{s}, k_{2}$ и $k_{3}$ из прямых измерений, т. е. без добавления в реакционную смесь какихлибо селективных эффекторов или нуклеофильных агентов, как в случае определения этих констант из стационарной кинетики (для обзора см. $\left.\left[{ }^{2}\right]\right)$.

Зависимости $p K_{s}, \lg k_{2}$ и $\lg k_{3}$ от $n$ показаны на рисунке. Видно, что увеличение длины углеводородной цепи в ацильной части соединений приводит к одинаковому увеличению $p K s$ и $\lg k_{2}$. Этим тиохолиновые эфиры как субстраты химотрипсина принципиально отличаются от аналогичных $n$-нитрофениловых эфиров карбоновых кислот, н- $\mathrm{C}_{n} \mathrm{H}_{2 n+1} \mathrm{C}(\mathrm{O}) \mathrm{OC}_{6} \mathrm{H}_{4} \mathrm{NO}_{2}$-П, для которых показано [3-5], что при изменении $n$ от 1 до 3 константа $k_{2} / K s$ практически не меняется, а начиная с $n=3$ (до $n=6)$ между $\lg \left(k_{2} / K s\right)$ и $n$ наблюдается линейная зависимость с наклоном около 0,4 , который, согласно результатам анализа, проведенного А. А. Клесовым и И. В. Березиным [5], вызван изменением $K s$ при постоянстве $k_{2}$ (собственно значений $k_{2}$ и $K s$ для реакции химотрипсина с серией п-нитрофенилкарбоксилатов определить не удалось).

В случае же тиохолиновых эфиров H- $_{n} \mathrm{H}_{2 n+1} \mathrm{C}(\mathrm{O}) \mathrm{S}\left(\mathrm{CH}_{2}\right)_{2} \stackrel{+}{\mathrm{N}}\left(\mathrm{CH}_{3}\right)_{3}$ наклон прямой в координатах $\lg \left(k_{2} / K s\right)$ от $n$ при увеличении $n$ от 1 до 3 составляет 0,93 (значения $k_{2} / K s$ для этой корреляции были получены из отдельных опытов как бимолекулярные константы скорости гидролиза

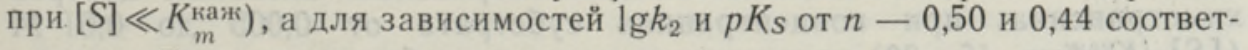
ственно. Так как для специфических субстратов химотрипсина, метило-

вых эфиров N-ацетил-L-аминокислот,<smiles>CCCCC(=O)NC(C)=O</smiles> 


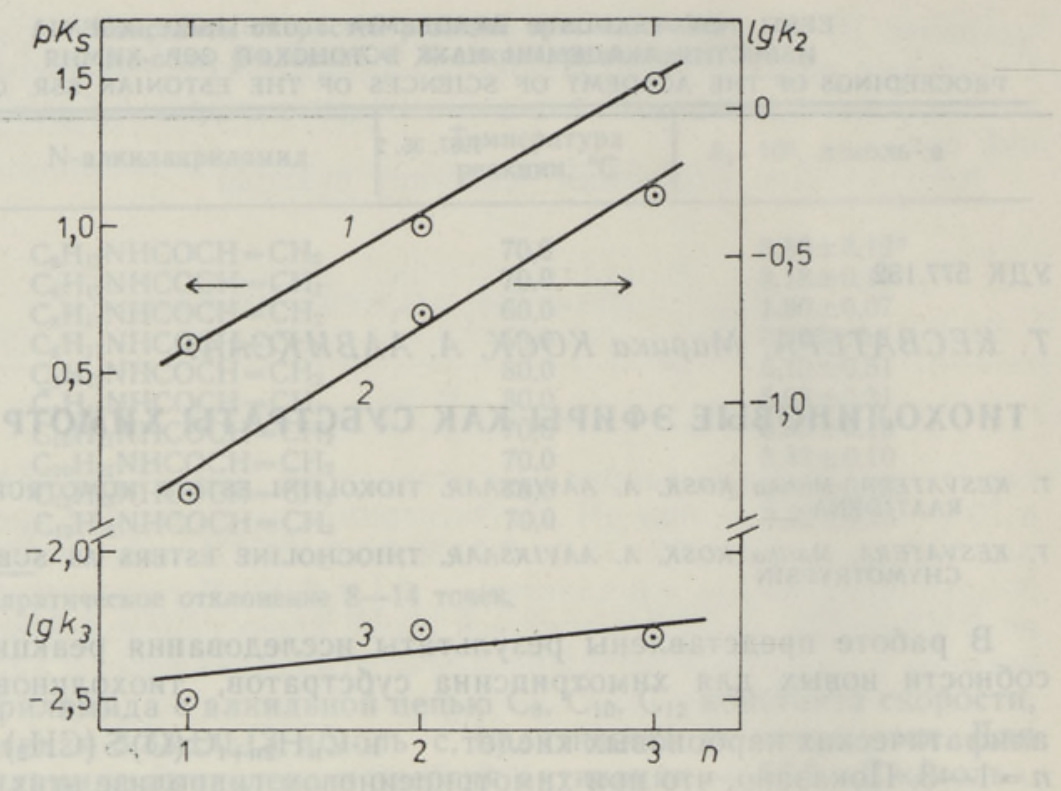

Зависимость кинетических констант реакции $\alpha$-химотрипсина с субстратами $\left[\mathrm{H}^{-} \mathrm{C}_{n} \mathrm{H}_{2 n+1} \mathrm{C}(\mathrm{O}) \mathrm{S}\left(\mathrm{CH}_{2}\right)_{2} \stackrel{+}{\mathrm{N}}\left(\mathrm{CH}_{3}\right)_{3}\right] \mathrm{Br}^{-}$(или $\left.I^{-}\right)$oт $n, 1-p K_{\mathrm{S}}, 2-\lg k_{2}, 3-\lg k_{3}$. Условия опытов: $25^{\circ} \mathrm{C}, \mathrm{pH} 7,5$, фосфатный буфер, нонная сила 0,15 . Анализ кинетических данных по предстационарной кинетике проведен, как описано в [ $\left.{ }^{2}\right]$.

прямые в координатах $\lg k_{2}$ и $p K s$ от $n(n=1-4)$ по данным [5] имеют наклоны 0,50 и 0,52 , то можно предположить, что взаимодействие ацильной части тиохолиновых эфиров алифатических карбоновых кислот с химотрипсином хорошо моделирует взаимодействие боковой цепи аминокислоты в его специфических субстратах с активным центром фермента, чего нельзя сказать о серии п-нитрофенилкарбоксилатов. Интересно отметить, что линейная зависимость $\lg \left(k_{2} / K s\right)$ от $n$ с наклоном 0,9 наблюдается также в реакции химотрипсина с имидазольными карбо-

ксилатами, $\quad$ - $\mathrm{C}_{n} \mathrm{H}_{2 n+1} \mathrm{C}(0)-\mathrm{N}_{\mathrm{N}}$, с $n=1,3,5\left[^{6}\right]$, для которых $k_{2}$ и $K_{S}$

отдельно не получены.

Слабая зависимость $\lg k_{3}$ от $n$ (см. рисунок) согласуется с литературными данными по деацилированию «неспецифических» ацилхимотрипсинов с короткой ацильной частью $[4,5,7,8]$.

Возможность прямого определения констант $K_{s}, k_{2}$ и $k_{3}$ из предстационарной кинетики в минутной шкале времени делает тиохолиновые эфиры карбоновых кислот удобными субстратами для исследования влияния реакционной среды на отдельные стадии химотрипсин-катализируемых реакций. Кроме того, бутирилтиохолин с соотношением $k_{2} / k_{3}$ около 80 может быть использован для титрования активных центров химотрипсина: при концентрациях субстрата от 0,005 до $0,01 \mathrm{M}$ $\left([S]_{0} / K_{m}^{\text {каж }}=15-30\right)$ величина начального «выброса» тиохолина равна концентрации активных центров фермента. Учитывая значение $\varepsilon_{412}=$ $=13600$ для комплекса тиохолина с реагентом Эллмана, наиболее удобным диапазоном концентраций фермента при его титровании можно считать $10^{-6}-10^{-5} \mathrm{M}$, где величина выброса имеет значения от 0,014 до 0,14 единиц оптической плотности, 


\section{ЛИТЕРА Т У РА}

1. Ellman, G. L., Courtney, K. D., Andres, V., Featherstone, R. M. A new and rapid colorimetric determination of acetylcholinesterase activity. - Biochem. Pharmacol., 1961, 7, N 1, 88-95.

2. Березин И. В., Мартинек К. Основы физической химии ферментативного катализа. M., $1977,171-267$.

3. Milstien, J. B., Fife, T. H. Steric effects in the acylation of $\alpha$-chymotrypsin. - Biochemistry, 1969, 8, N 2, 623-627.

4. Marshall, T. H., Akgün, A. The specificity of porcine elastase and $\alpha$-chymotrypsin. Effect of fatty acid chain length in a homologous series of nitrophenyl esters. J. Biol. Chem., 1971, 246, N 19, 6019-6023.

5. Клесов А. А., Березин Н. В. Ферментативный катализ, І. М., 1980, 111-127.

6. Kogan, R. L., Fee, J. A., Fife, T. H. The mechanism of specific acylation of the active site of $\alpha$-chymotrypsin by $\mathrm{N}$-acyl-imidazoles. - J. Amer. Chem. Soc., 1982, 104, N $13,3569-3576$.

7. Fife, T. H., Milstien, J. B. Steric effects in the deacylation of acyl-chymotrypsins. Biochemistry, 1967, 6, N 9, 2901-2907.

8. Мартинек К., Доровска В. Н., Варфоломеев С. Д. Стерические, индукционные и специфические эффекты при деацилировании ацил- $\alpha$-химотрипсинов - производных алифатических карбоновых кислот. - Биохимия, 1972, 37, вып. 6, 1245-1250.

Ннститут химической и биологической физики Академии наук Эстонской ССР

Ннститут химии

Академии наук Эстонской ССР
Поступила в редакцию 26/XI 1986 